\title{
Iterating Toward Openness: Lessons Learned on a Personal Journey
}

\author{
David Wiley \\ Lumen Learning, david.wiley@gmail.com
}

\section{Editors' Commentary}

For nearly 20 years David Wiley has been on the frontlines of the open education movement, working on tools, licenses, infrastructure, research, and advocacy. In this chapter, David shares personal and hard-won insights from his mission to implement the ideas and promises of Open, including the power of combining digital content with open licenses, the pointlessness of producing OER that is never reused, the kind of change required to realize the potential of Open, the need to redefine OER quality in terms of its effectiveness, and the importance of addressing specific problems. The chapter concludes with a commentary on the infrastructure that is necessary to truly expand educational opportunities and potential.

I've spent my entire career watching very smart and well-meaning people claim that the unique features of their repository of open educational resources (OER) (or learning objects the decade before that) will finally result in significant teacher use, or that their authoring tools are so wonderfully easy to use that they will create a breakthrough in faculty use of OER. While some repositories and some authoring tools are certainly easier to use than others, a website simply cannot overcome the gargantuan inertia and imprinted behaviors associated with textbook use in higher education. And that's my current

How to cite this book chapter:

Wiley, D. 2017. Iterating Toward Openness: Lessons Learned on a Personal Journey. In: Jhangiani, R S and Biswas-Diener, R. (eds.) Open: The Philosophy and Practices that are Revolutionizing Education and Science. Pp. 195-207. London: Ubiquity Press. DOI: https://doi.org/10.5334/bbc.o. License: CC-BY 4.0 
goal - to replace the expensive, rights-restricted textbooks currently in use in higher education with OER. OER are materials that meet the criteria of free plus permissions - they are (1) freely available and (2) come with an irrevocable grant of permission to engage in the $5 \mathrm{R}$ activities - retain, reuse, revise, remix, and redistribute. It's true that better tools will help move the field forward, but tools can't get us all the way there (or even close to there, honestly). To borrow an analogy from Hubert Dreyfus, trying to influence the textbook adoption process of the nation's faculty by making a website is a bit like trying to get to the moon by climbing trees. Yes, you can make some initial progress that moves you a slightly closer to the goal and feels encouraging, but the whole approach is doomed from the beginning.

In this chapter I share some of the lessons I've learned as I've slowly iterated toward openness over the last twenty years, in hopes that they can help move higher education toward OER more quickly and efficiently.

\section{Finding Open}

In 1997 I finished my BFA in Music at Marshall University and was working as the institution's first webmaster. No one knew what a webmaster was supposed to do, myself included, and I enjoyed broad latitude in my day to day activities. In addition to chairing the committee that determined who owned the rights to content created by faculty for online courses (who better than the webmaster, right?), I spent a lot of time exploring new technologies.

One day I was playing around with Javascript trying to build a calculator that could be embedded in a webpage. I will remember that afternoon for the rest of my life. It suddenly occurred to me that once this calculator was created and published online, the whole world could use it. Well, more than that the whole world could use it at the same time. That affordance of being digital made it critically different from a physical calculator that only one person at a time can use. Of course economists and others had understood the difference between rivalrous and nonrivalrous resources for years, but this discovery was completely new to me.

It was quite vogue at the time among Slashdot-reading free software advocates to think poorly of Bill Gates. I connected my calculator discovery to his incredible wealth immediately. Silently shaking my head, I thought something along the lines of 'This is how you become a billionaire - create something that costs nothing to copy and then sell copies for US\$150 each. It's like printing money!' Then the better angels of my nature took the mic and suggested, 'The other side of the coin is this - once you create something digitally, it can be used by everyone around the world at no additional cost.' Not just tools like calculators, I realized, but syllabi, articles, chapters, entire journals and whole textbooks... This realization hit me like a bolt from the blue. It was almost like in a movie, where the clouds part and a ray of sunshine breaks through. In that 
moment I had the undeniable impression that because I understood it, I was responsible to act on this knowledge.

In 1998 I left Marshall and headed to Brigham Young University to take a PhD in Instructional Psychology and Technology. Earlier that year, Eric Raymond, Bruce Perens, and others had proposed the term 'open source' as an alternative to 'free software.' I was particularly struck by the pragmatism of their arguments. Cutting the grass of the tiny lawn next to our apartment in Orem that summer, I realized that open licenses were the key ingredient I was missing. Digital formats make the broad sharing of educational materials technologically possible; open licenses make the broad sharing of educational materials legal.

\section{Making Open}

And so I set out on a journey with a general direction but without a specific destination. The power and pragmatism of the open source model, the almost magical nature of digital content, and the way these combined to catalyze the wonders of the internet fascinated me. It seemed like an incredibly promising approach that could transform education and provide huge benefits to people in the process.

I spent the first ten years of this journey working with a number of collaborators to build very specific bridges across very specific chasms between where we were and where we wanted to be in terms of bringing the power of open to education. This included creating and propagating the 'open content' meme, creating the first open licenses for something other than software, including the Open Content License and Open Publication License (later superseded by the Creative Commons licenses), persuading individuals and institutions to begin using these licenses to share their open educational resources, and providing technology infrastructure to university-based OpenCourseWare initiatives around the globe. Years later, thousands of universities, individuals, and organizations were sharing openly licensed educational materials online.

To my dismay, however, almost no one was using OER in formal settings. Yes, projects like MIT open courseware (OCW) published evaluation reports showing that individual learners from the around the world were coming to their website and learning things. Many of their stories were incredibly moving. But the open education movement, as we were calling it, wasn't actually impacting formal education. People were openly licensing materials left and right, but faculty continued to adopt expensive commercial textbooks for their courses. For a year or so it felt like every week saw another major OCW announcement from a major university around the world. But while they all wanted to publish OER, no one wanted to use OER. In retrospect, perhaps this was because the early participants were all extremely prestigious schools. The rivalries between these schools being well understood, would we really expect faculty from Ivy League A to reuse anything created by faculty from Ivy League B? 
This situation frustrated me to no end. What was the point of openly licensing educational materials if no one was going to use them? (Early on, the answer to this question was 'publicity.) And why were people calling this pattern of behavior 'sharing?' If I offer you some of my French fries, but you don't take any, have I shared with you? No. Rather than calling it open sharing, the first decade of work in the open education movement would be more accurately characterized as open offering. If no one was going to reuse these openly licensed materials, the whole exercise was literally pointless.

\section{Reusing Open}

In 2007 a graduate student walked into my office at Utah State University to inform me that Utah state law had changed recently, making it legal to open fully online charter schools. I responded with a confused, 'That's interesting... thanks for sharing.' He pushed ahead, 'I think this is a great opportunity for you to put into practice all your fancy theories about open content and education.' He didn't quite say 'put up or shut up', but close enough. I began discussing the idea in earnest with colleagues in the Center for Open and Sustainable Learning (COSL), the research unit I founded and directed at USU. This seemed like a great opportunity to make progress toward our stated mission:

At the Center for Open and Sustainable Learning, we believe that all humans beings are endowed with a capacity to learn, improve, and progress. Educational opportunity is the mechanism by which we fulfill that capacity. Therefore, free and open access to educational opportunity is a basic human right. When educational materials can be electronically copied and transferred around the world at almost no cost, we have a greater ethical obligation than ever before to increase the reach of opportunity. When people can connect with others nearby or in distant lands at almost no cost to ask questions, give answers, and exchange ideas, the moral imperative to meaningfully enable these opportunities weighs profoundly. We cannot in good conscience allow this poverty of educational opportunity to continue when educational provisions are so plentiful, and when their duplication and distribution costs so little. (COSL website)

We decided to create something new - a major OER initiative that would not produce any OER, but instead would be dedicated to reusing OER produced by others.

This was the genesis of the Open High School of Utah (OHSU; which later changed its name to Mountain Heights Academy), a charter school whose charter documents commit it to using OER for its core curriculum materials instead of commercial resources. This turned out to be much harder to do than 
it sounded. Yes, the global collection of OER was still relatively young in the mid-2000s, but more importantly the school's new faculty, administration, and board would need significant, ongoing professional development to understand what it was we were trying to do and why it was important.

I learned first hand that this degree of systemic change - changing the fundamental way schools and teachers find, procure, use, and continuously improve curriculum resources - is not the kind of change you can create by conducting a workshop. It's also not the kind of change you can create by simply developing a tool with a simpler user interface (UI) or a bigger library of content. This degree of change requires sustained attention by people who care deeply about it succeeding, and nothing short of that will work.

\section{Comparing Open}

As I talked with people about our early success with OHSU, I began to hear the discourse around OER shift. A few years earlier, people demurred when you told them about OER because they were certain none existed in their discipline. As we were able to demonstrate that sufficient OER did exist, the excuse changed to concerns about quality. The old notion that 'you get what you pay for' was simply too deeply engrained in people. Yes, I could convince someone that OER existed for their courses, but they couldn't believe that anything freely available could be worth their time.

In 2008 I decided to shift strategies and institutions. I moved from Utah State University to Brigham Young University, and decided to intensely focus my research on cutting the legs out from under the quality arguments around OER. I hoped to be able to successfully fight intuition with data.

The first problem with fighting the public's perceptions of 'quality' of educational materials is that the public is completely and utterly wrongheaded in their thinking about quality. Let me explain.

As success at OHSU translated into adoption of OER in place of commercial science textbooks in traditional Utah high schools and middle schools, my graduate students and I engaged in several research studies. At the same time evidence was emerging that students who were assigned OER did as well as their commercial textbook using peers on the state's standardized science tests, a Brigham Young University (BYU) graduate student completed a master's thesis examining the quality of the OER they were using. She concluded that the OER were of lower quality compared to commercial materials, based on a structural and aesthetic review of the OER. There were problems with the layout and graphic design of the OER, there were copyediting shortcomings, there were pixilated images in the text, etc. By any aesthetic or 'production values' measure, the OER were lower quality than the materials being provided by publishers. However, students were learning the same amount - in some cases more - from the OER. 
This contradiction inevitably lead me to ask, 'what is quality?' When given the choice between materials that are beautiful but result in lower learning and materials that are far less beautiful but result in better learning, which will we call 'higher quality?' (If you had a beautiful hammer that drove nails poorly, and an ugly hammer that drove nails effectively, which would you call higher quality?) What is the primary purpose of educational materials? Is it to win a beauty contest, or to support learning?

Traditional publishers were quick to latch onto and propagate the 'OER are low quality' message. For traditional publishers, quality was purely a function of editorial process and had literally nothing to do with student learning. By making 'quality' equivalent with expensive graphic design, editorial, photography, other artwork, and other creative processes publishers sought to set 'quality' out of the economic reach of fledgling OER initiatives. By shouting from the rooftops that the quality of an educational resource ought to be judged by the learning it facilitates, I hoped to change the fight into one that OER could win. This is why, when talking about educational materials, I typically refuse to use the word quality and instead use effectiveness. If materials are less effective, who cares how beautiful they are? If they are effectively supporting learning, what are we arguing about?

The discussion about aesthetics versus effectiveness also needs to include the issue of cost. As my colleague Lane Fischer likes to say, 'with OER there are two ways to win.' What he means is this: in any study comparing the cost of and level of student learning facilitated by commercial materials and OER, OER will always cost less. Therefore, there are only three possible outcomes - OER save money but support poorer learning, OER save money and support the same learning, and OER save money and support better learning. Of the three possible outcomes, two of them favor OER. Getting the same outcomes for less money is obviously a win, and finding better student outcomes for less money is like hitting a walk-off grand slam. This is why 'student success per dollar,' a measure of the percentage of students who receive a $\mathrm{C}$ or better final grade against the cost of textbooks required for a course, continues to fascinate me. When we let commercial publishers dictate the terms of comparison - graphic design, editorial process, peer review - weve already lost. We need to shift the dialog so that OER are judged on the only metric that actually matters - effectiveness. If we can push farther, to measures of effectiveness per dollar spent, we can win.

\section{Following Open}

As I pivoted to this new focus I had the opportunity to partner with Kim Thanos and others on a grant-funded project called Kaleidoscope. This was a Gates-funded project with goals that may sound familiar. We committed to avoid creating new OER and instead reuse existing OER to replace textbooks in classes at eight community colleges around the United States. We learned 
again that helping faculty think differently about where they find teaching and learning resources, how they select them, and how they use them to support learning is significantly more complicated than it might seem at first. Again, no single repository or tool could catalyze the degree of change we hoped to see. Of course, making it easier rather than harder to find and remix OER aided our cause, but the main determinant of the success of Kaleidoscope was the hundreds of hours of encouragement, training, and support provided by the core team to the faculty partners (together with a willingness on the part of the core team to be yelled and cried at in frustration from time to time by faculty.)

Teaching, it turns out, is a deeply human endeavor. Those humans who teach have a wide range of deeply entrenched and conflicting habits, biases, incentives, and values. Building your WhizBang app with Twitter Bootstrap or using the IEEE LOM metadata standard isn't going to overcome them. From Kaleidoscope we learned, yet again, that large-scale change is best (and perhaps only) accomplished by good old-fashioned handholding, support, and encouragement. More on our process for doing this below.

As Kaleidoscope ended, we began the process of applying for a renewal grant for a second phase of Kaleidoscope in which we would add 20 more institutional partners. I began to appreciate just how much we had learned about OER adoption. We had learned a lot about how to do it wrong, and something about how to do it effectively. Originally I had thought that when the grant funding ended I would turn my full focus back to my tenured faculty position, and that Kim and the others would do likewise. But I began to realize that if we all went back to our previous jobs that learning would go with us. I can remember specifically asking myself, 'What? You're going to write an article about everything you learned about OER adoption, publish it, and then someone else is going to quit their job and go apply all the lessons you learned to move OER adoption forward around the country?'

The unthinkable started happening before I even realized it - I seriously began to consider stepping away, at least temporarily, from academia.

Then several things happened at once. The Gates Foundation approved our request for renewal funding, and Kim and I founded Lumen Learning as the entity that would carry this important work forward. But I was still on the fence about what to do personally. The most sensible path forward was to remain full-time at BYU and have Lumen buy out a portion of my time. After all, not only was I tenured at BYU, with a matching contribution to my retirement each month from the university, but BYU is one of the few institutions in the US that also has a pension plan. Leaving BYU would mean walking away from an incredibly secure future for my family. However, the more I talked with Kim about the kind of change we thought we could create in the world, the more my wife Elaine and I felt that I had a responsibility - a calling, or a sacred obligation - to keep pushing forward my work on OER.

We decided I would apply for a year of 'leave without pay' from BYU for calendar 2013 and see what we could make happen in that period. Almost 
immediately after making this decision, I was awarded a fellowship by the Shuttleworth Foundation. The Shuttleworth Fellowship would replace my salary for a year on the condition that I focus my full attention on supporting OER adoption. It was an incredible, timely confirmation that we had made the right choice.

\section{Designing Open}

Since we founded Lumen Learning in October 2012 I've learned even more about OER adoption. We've worked our way through successes and failures to a very straightforward model of supporting faculty in making the move from commercial textbooks to OER. The first lesson remains and will remain systemic change requires dedicated, ongoing support from people who care. I believe the second lesson is wrapped up in the question how much instructional design value can we realize in the shortest amount of time and effort from faculty?'

Any seasoned instructional designer will tell you that the overwhelming majority of faculty feel like their terminal degree in their discipline is enough to make them a decent teacher. Even suggesting to most faculty members that their instruction could be improved is seen as insulting. However, once every decade or so a major change comes along that sends faculty looking for help. For example, the opportunity to teach online using a learning management system will send many first-timers looking for support from their Center for Teaching and Learning. In the hands of a skilled instructional designer, the help provided won't end with 'point here, click there,' but will include course redesign work that significantly improves the effectiveness of the course. The improvements are not characterized as strengthening weaknesses in the faculty's current practice, but as new affordances offered by new technologies the faculty member can now leverage for their students' benefit. These infrequent and narrow windows of time are, generally speaking, the only times when faculty are open to significantly improving their courses.

When handled adeptly, the move from traditional materials to OER creates a window of opportunity to improve the quality of teaching and learning. (While adopting an open textbook in place of a commercial textbook saves students money and is generally a good thing, a straight across swap of this kind does not create such a window.) Lumen's model for working with faculty leverages the novelty of OER to covertly introduce faculty to a range of basic instructional design principles.

For example, no principle of instructional design is more basic than assuring that the stated goals of a course match what you're actually assessing, and that these both match what students are actually reading about and talking about in class. Instructional designers refer to this as 'alignment,' and the general principle is that course learning outcomes should be directly aligned with 
assessments, which should in turn be directly aligned with readings, videos, discussions, and other activities.

Many faculty believe that the first step of using OER in place of commercial textbooks is to find suitable OER. This is one of Lumen's primary instructional design attack vectors. We scaffold the OER selection process for faculty by providing them with a spreadsheet (which I will slightly oversimplify here) in which they list their course learning outcomes in Column A. We then provide them with several previously license-vetted collections of OER related to their course, and encourage them to select one or more OER they feel will best support student mastery of each outcome. The link(s) to these OER go in Column B, so that they remain visually aligned straight across from the course learning outcomes they support. Finally, a description of the assessments appropriate for each outcome goes in Column C, again creating a clean horizontal alignment from each course learning outcome, to the content students will use to study it, to the assessment they will take to demonstrate they have mastered it.

This simple process, one of several we do with faculty, can usually be completed in a one-day workshop, but creates a wide range of benefits to teaching and learning. For example, faculty frequently realize that their course learning outcomes are underdeveloped, and they strengthen, clarify, and add to them. This is a significant professional development activity in and of itself. Faculty also frequently realize that they're covering much more content in their class than they ever intended to, and make comments like, 'I guess I thought if I'm going to make students buy a US\$160 book, I wanted them to feel like they're getting their money's worth, so I covered every chapter.' Eliminating these less important topics provides faculty with extra time to cover the topics the course is actually supposed to focus on in more depth. Perhaps most telling of all, students whose faculty go through this process often provide feedback on end of semester course evaluations along the lines of 'I loved that the things we discussed in class were actually related to the readings we did before class!' The teaching and learning benefits of this kind of small structural improvement are so powerful and obvious that students will mention the difference in an open-ended comment box, unprompted.

\section{Defending Open}

'Serious' instructional designers and learning scientists will no doubt complain that Lumen Learning's simplified approaches to working with faculty gloss over the subtlety and nuance of their fields, and as an instructional designer I fully agree. The approach we have evolved at Lumen is not one that tries to give every faculty member a graduate degree in learning sciences, rather it is a ruthlessly pragmatic approach that asks 'how much can we improve student learning during our interactions with these faculty? What are the highest impact, lowest 
effort things that faculty probably aren't doing, and how can we integrate them into the OER adoption process?'

This is the point where academics who venture outside the Ivory Tower are typically attacked by their peers. 'How dare you defile the purity of our discipline! How dare you water it down for popular consumption!' One of my favorite sayings - I wish I knew you said it - is 'In theory, there's no difference between theory and practice. But in practice, there is. This is nowhere more obvious than in trying to support the broad adoption of OER together with effective teaching and learning practices. The bridge from efficiently espousing theories in the classroom to effectively supporting their implementation in the world at times feels like a rope bridge across a great chasm - tenuous, swaying with every gust of wind. But I must admit that building this bridge again and again, and helping people cross it, is some of the most exciting and rewarding work I have ever done.

I have become an outspoken advocate for the idea that academics need to engage more directly in real world work, and do it in collaboration with their students whenever possible. I was significantly emboldened in my thinking and speaking out on this topic by Tom Reeves, whose work on socially responsible research continues to be an inspiration to me. He challenges educational researchers to stop focusing our research on things (e.g., learning analytics or $3 \mathrm{D}$ printing) and instead to start focusing our research on problems (e.g., poverty or illiteracy). As I continue to engage in research with my colleagues in the Open Education Group, including John Hilton and Lane Fischer, we fight to maintain this perspective and not let our research devolve into inert studies of OER. Those working in open education, whether as advocates, creators, teachers, researchers, or in other capacities, would do well to continually focus and refocus their efforts on solving specific problems.

\section{Growing Open}

At the beginning of the chapter I said that I embarked on a journey in a general direction but without a specific destination. Almost 20 years later, I can now see the specific place I am hoping we arrive in the future.

To understand the future of open we must first understand the present of open. In as much as open means free plus permissions, the primary function of open is to create opportunities and expand potential. Consequently, I believe that all meaningful activity in the future of open will fall into one of two categories: further expanding educational opportunities and potential by means of open, and directly supporting people in actively taking advantage of these additional opportunities and potential. You might say that the future of open is about simultaneously increasing negative liberty and positive liberty for teachers and learners.

In order to further expand educational opportunities and potential, we must move beyond our current, narrow conceptions of OER (read: textbooks with 
open licenses) to a more expansive view that includes all of the core pieces of the intellectual infrastructure of education. When each of these components is opened, I refer to the collection as the Open Education Infrastructure:

- Open Competencies.

- Open Educational Resources.

- Open Assessments.

- Open Credentials.

The full stack must be open because there are critical interdependencies between the components. Until the full stack of our intellectual infrastructure becomes open, truly democratized innovation and permissionless innovation will be impossible.

Open Competencies exist, but they exist primarily as isolated bullets in scattered openly licensed syllabi. These competencies need to be harvested, synthesized, and mapped together in order to create the disciplinary equivalent of Google Maps (actually, OpenStreetMaps would be a better metaphor). In Introduction to Psychology, for example, what are the primary topics? How do they relate to each other? What are the prerequisite relationships between them? What are their relative difficulties? Annotating these Open Competencies using aggregate data from student interactions with OER and student results on Open Assessments will provide us with empirically validated maps of (and myriad pathways through) the disciplines. OER, Open Assessments, and Open Credentials can then be aligned with Open Competencies.

Open Educational Resources are, of course, the most pervasive and best understood component of the Open Education Infrastructure. However, we will need to move beyond the idea that OER are a textbook substitute. The textbook metaphor carries too much conceptual baggage with faculty for the metaphor to be useful in the long term.

Substantive intellectual and practical work remains to be done on Open Assessments. First, questions must be answered regarding the integrity and security of assessments that are openly licensed. Second, as students and faculty (neither of whom are trained in creating valid, reliable assessments) create and contribute a wide range of Open Assessments to the community, we will need to develop techniques for evaluating and improving assessments on the ground and contributing these improvements back to the community. The assessment pilot testing methods used by companies like Educational Testing Service (ETS) may serve as inspiration here.

Open Credentials are certifications that learners own completely and can reuse and redistribute without involving a third party like the college registrar. They may be awarded at the level of traditional degrees or may be aligned with specific Open Competencies and awarded at the individual competency level. These credentials can be regrouped and remixed by learners to highlight different aspects of the learner's expertise, depending on the context in which 
they are presenting themselves. Each credential must be tamper-proof so that those who evaluate the Open Credential can validate and trust its origin. Mozilla's work on the Open Badges Infrastructure has demonstrated one method of awarding an Open Credential to a learner. While much of the intellectual work on Open Credentials has come a long way, it has recently stagnated because of the public's distaste for the 'badge' branding.

As we engage in the unglamorous, workaday slog of laying the rails and paving the roads of the Open Education Infrastructure, we also need to provide teachers and learners with help. Specifically, they need help understanding what new opportunities now exist and they need to see positive, relatable examples of people like themselves leveraging this new potential in their own classrooms and online courses. Yes, new tools will be important (the freight trains, cars, and long-haul trucks to run on the rails and roads), but these tools will be of absolutely no use if we do not provide significant, proactive support to faculty and learners that teaches them how to use them.

As I have repeated over and over again, we are engaged in a systemic change process - a human change process. Massive changes like those we hope to enable by building out the Open Education Infrastructure begin with small steps, like helping faculty create, share, and adopt OER. These steps must be carefully supported and encouraged by people who are committed to their immediate success and who have the long-term vision of what education can become.

\section{References}

AECTx: David Wiley: You Have SuperPowers. [Video file]. Retrieved from https://www.youtube.com/watch?v=DuBBhjMnzcg

Bootstrap. (2016). Main page. Retrieved from http://getbootstrap.com/

Creative Commons. (2016). About the licenses. Retrieved from https://creative commons.org/licenses/

Lumen Learning. (2014). Home page. Retrieved from http://lumenlearning. com/

MIT OpenCourseWare. (2006). 2005 Program evaluation findings report. Retrieved from http://ocw.mit.edu/ans7870/global/05_Prog_Eval_Report_ Final.pdf

Mountain Heights Academy. (2016). Welcome to Mountain Heights Academy. Retrieved from http://www.mountainheightsacademy.org/

Next Generation Learning Challenges. (2015). Cerritos college with Lumen Learning. Retrieved from http://nextgenlearning.org/grantee/cerritoscollege-lumen-learning

Open Content. (1999). Open publication license. Retrieved from http://open content.org/openpub/

Open Education Group. (2016). Welcome. Retrieved from http://openedgroup. org/ 
Open Source Initiative. (2012). History of the OSI. Retrieved from https://opensource.org/history

OpenStreetMap. (2016). Welcome to OpenStreetMap! Retrieved from http:// www.openstreetmap.org/

Price, J. L. (2012). Textbook bling: An evaluation of textbook quality and usability in open educational resources versus traditionally published textbooks. (2012). All Theses and Dissertations. Paper 3327. Retrieved from http:// scholarsarchive.byu.edu/cgi/viewcontent.cgi? article $=4326 \&$ context $=$ etd

Reeves, T.C. (2016). Socially responsible educational technology research. Retrieved from https://www.academia.edu/19294287/Socially_Responsible_ Educational_Technology_Research

Shuttleworth Foundation. (2016). Fellowship. Retrieved from https://shuttle worthfoundation.org/fellows/

Slashdot. (2016). Stories. Retrieved from https://slashdot.org/

SourceForge. (2016). eduCommons. Retrieved from https://sourceforge.net/ projects/educommons/

Thierer, A. (2014). Embracing a culture of permissionless innovation. Retrieved from http://www.cato.org/publications/cato-online-forum/embracingculture-permissionless-innovation

von Hippel, E. (2005). Democratizing innovation. Cambridge, MA: The MIT Press. Retrieved from http://web.mit.edu/evhippel/www/democ1.htm

Web Archive. (1999). OpenContent. Retrieved from https://web.archive.org/ web/19990117060918/http://www.opencontent.org/home.shtml

Web Archive. (2006). The center for open sustainable learning. Retrieved from https://web.archive.org/web/20060712031919/http:/cosl.usu.edu/

Wikipedia. (2016a). Rivalry (economics). Retrieved from https://en.wikipedia. org/wiki/Rivalry_(economics)

Wikipedia. (2016b). Learning object metadata. Retrieved from https:// en.wikipedia.org/wiki/Learning_object_metadata

Wikipedia. (2016c). Negative liberty. Retrieved from https://en.wikipedia.org/ wiki/Negative_liberty

Wikipedia. (2016d). Positive liberty. Retrieved from https://en.wikipedia.org/ wiki/Positive_liberty

Wiley, D. (2016, January 29). The Consensus around "Open”. [Web log comment]. Retrieved from http://opencontent.org/blog/archives/4397

Wiley, D., Hilton III, J. L., Ellington, S., \& Hall, T. (2012). A preliminary examination of the cost savings and learning impacts of using open textbooks in middle and high school science classes. The International Review of Research In Open And Distributed Learning, 13(3), 262-276. Retrieved from http://www.irrodl.org/index.php/irrodl/article/view/1153/2256

Wiley, D. (2014, July 15). The Open Education Infrastructure, and Why We Must Build It. [Web log comment]. Retrieved from http://opencontent.org/ blog/archives/3410 
